\title{
Observational Study of the Safety of an Ultra-Rush Sublingual Immunotherapy Regimen to Treat Rhinitis due to House Dust Mites
}

\author{
Albert Roger $^{\mathrm{a}}$ José-Luis Justicia ${ }^{c}$ Luis Ángel Navarro ${ }^{\mathrm{b}}$ José Luis Eseverri ${ }^{\mathrm{d}}$ \\ Jeroni Ferrès ${ }^{e}$ Alfons Malet ${ }^{f}$ Víctor Alvàg \\ ${ }^{a}$ Allergy Unit, University Hospital Germans Trias i Pujol, Badalona, ${ }^{b}$ Allergy Service, Hospital Lluis Alcanyis, Xativa,

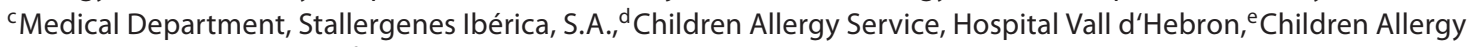 \\ Service, Hospital Sant Pau, ${ }^{\mathrm{f}}$ Al-lergo Centre, and, ${ }^{9}$ Stallergens Ibérica S.A., Barcelona, Spain
}

\section{Key Words}

Asthma $\cdot$ Dermatophagoides $\cdot$ Rhinitis $\cdot$ Sublingual immunotherapy $\cdot$ Ultra-rush

\begin{abstract}
Background: Ultra-rush regimens for administering sublingual immunotherapy to patients with allergies are becoming more widespread. We aimed to assess treatment safety for patients with allergic rhinitis with or without asthma caused by Dermatophagoides house dust mites. Methods: This observational study at 5 Spanish centers included 218 patients aged 4-64 years, of whom 117 were women and 122 were under 15 years old. Ultra-rush regimen consisted of incremental doses of an allergen extract comprising a $50 \%$ mixture of Dermatophagoides pteronyssinus and Dermatophagoides farinae (30, 60, 120, 240 IR every $30 \mathrm{~min})$ followed by maintenance therapy. Adverse reactions were monitored and asthmatic patients underwent spirometric testing at baseline and after each dose. Follow-up was scheduled after 2 weeks of maintenance with 240 IR three times a week. Results: Five patients had to modify ultra-rush regimen because of mild local adverse reactions. In total, $32 \mathrm{ad}$ -
\end{abstract}

verse reactions were reported in 27 patients during the ultrarush regimen. Seven of these events were local gastrointestinal reactions, and the remaining 17 were local reactions, mainly labial or mouth itching and burning. Eight events were systemic reactions [rhinitis $(n=3)$, general malaise $(n=$ $1)$, general malaise and vomiting $(n=1)$, dizziness $(n=1)$, asthma $(n=1)$, dyspnea $(n=1)$. All adverse reactions were mild or moderate. Serious adverse events or life-threatening anaphylactic reactions were not reported. Conclusions: High-dose sublingual immunotherapy with Dermatophagoides allergen extracts can be safely administered in an ultrarush regimen, although its usefulness and benefit for perennial allergens (e.g. house dust mites) must be evaluated.

Copyright $\odot 2010$ S. Karger AG, Basel

\section{Introduction}

Besides allergen avoidance, the only treatment available that changes the natural history of the disease in patients with allergic rhinitis or asthma is specific immunotherapy. The first immunotherapies were administered as subcutaneous injections, but concerns about the

\section{KARGER}

Fax +41613061234 E-Mail karger@karger.ch www.karger.com
(C) 2010 S. Karger AG, Basel

$1018-2438 / 11 / 1541-0069 \$ 38.00 / 0$

Accessible online at:

www.karger.com/iaa
Correspondence to: Dr. José-Luis Justicia

Medical Department, Stallergens Ibérica S.A.

C/Ramón Turró 91

ES-08005 Barcelona (Spain)

Tel. +34932 219 611, Fax +34932 259 829, E-Mail jjusticia@ stallergens.es 
risk of severe adverse reactions [1] prompted clinicians to try other routes, and sublingual swallow immunotherapy has been previously validated [2]. This route of administration offers several advantages, especially for children, where it is safe and easily administered [3].

The efficacy of sublingual swallow immunotherapy has been demonstrated for diseases such as allergic rhinitis [4] and asthma [5] and its safety has been demonstrated in both children and adults [6]; therefore it is now considered a useful alternative to subcutaneous injections $[2,7,8]$. Sublingual immunotherapy (SLIT) regimens have traditionally an induction phase of updosing lasting approximately 2-3 weeks. Shorter regimens could simplify the administration and could be better accepted by patients, favoring their adherence to therapy. Recently ultra-rush regimens with induction phases lasting less than $2 \mathrm{~h}$ have been tried [9-13]. These studies have demonstrated the safety and tolerability of ultra-rush regimens in a few randomized placebo-controlled trials performed with cypress pollen [9] and grass pollen [10, 11] and also in some observational studies $[12,13]$.

Nevertheless, additional and larger studies with other types of allergens are needed to further confirm the safety of such regimens [14], therefore we performed an observational study in a clinical practice setting to assess the safety of an ultra-rush sublingual regimen in patients with rhinitis with or without asthma (intermittent and mild or moderate persistent asthma) caused by house dust mites of the genus Dermatophagoides.

\section{Patients and Methods}

This was a non-randomized, prospective, open-label multicenter, observational study of the safety and tolerability of a high dose of house dust mites in an ultra-rush swallow SLIT regimen. The study was conducted in routine clinical practice between July 2005 and September 2006 in 5 Spanish hospitals - 4 in the metropolitan region of Barcelona (Al-lergo Centre, Hospital Germans Trias i Pujol, Hospital Materno-Infantil Vall d'Hebron, and Hospital Sant Pau) and 1 in Xativa, Valencia (Hospital Luís Alcanyis).

\section{Patients}

Patients with allergic rhinitis aged between 4 and 64 years old with or without accompanying intermittent or mild-moderate persistent asthma were considered for inclusion in the study. The responsible allergen was confirmed to be house dust mites of the genus Dermatophagoides. Allergic rhinitis was documented from the medical records (perennial symptoms) and the allergen sensitization was determined by positive skin-prick tests to these allergens, and serum levels of specific IgE of class 2 or greater $(>0.7 \mathrm{kU} / \mathrm{l})$.

As this study was conducted in a routine clinical practice, patients also had to meet the criteria for prescription of allergen im-
Table 1. Summary of the dosing regimen

\begin{tabular}{lllll}
\hline $\begin{array}{l}\text { Time } \\
\text { min }\end{array}$ & $\begin{array}{l}\text { Number of } \\
\text { applications }\end{array}$ & $\begin{array}{l}\text { Volume } \\
\text { administered } \\
\mathrm{ml}\end{array}$ & $\begin{array}{l}\text { Dose } \\
\text { administered } \\
\text { IR }\end{array}$ & $\begin{array}{l}\text { Total cumulative } \\
\text { dose administered } \\
\text { IR }\end{array}$ \\
\hline 0 & 1 & 0.1 & 30 & 30 \\
30 & 2 & 0.2 & 60 & 90 \\
60 & 4 & 0.4 & 120 & 210 \\
90 & 8 & 0.8 & 240 & 450 \\
\hline \multicolumn{5}{l}{ IR = Index of reactivity. } \\
a 1 application $=0.1 \mathrm{ml}=30$ IR. \\
\hline
\end{tabular}

munotherapy according to the practice of the attending allergist. Patients with autoimmune diseases, serious chronic inflammatory diseases, malignant disease, emphysema, bronchiectasis, $\beta$ blocker treatment, suspicion of alcohol abuse, severe asthma, and other contra-indications for immunotherapy were excluded.

The study was approved by the corresponding ethics committee. All patients were informed of the nature and objectives of the study and all patients (or their parents or legal guardians if applicable) signed an informed consent.

\section{Treatment and Study Procedures}

A 50\% mixture of Dermatophagoides pteronyssinus and Dermatophagoides farinae was used at a concentration of $300 \mathrm{IR} / \mathrm{ml}$ and administered as sublingual drops (Staloral 300, Stallergenes SA, Antony, France). The in-house reference index-of-reactivity (IR) is a measure of biologic potency (skin reactivity) used to describe the strength of an allergen extract; $100 \mathrm{IR} / \mathrm{ml}$ is defined as the concentration eliciting, by means of skin prick testing, a geometric mean wheal size of $7 \mathrm{~mm}$ in diameter in 30 patients sensitive to the corresponding allergen.

The induction phase was undertaken in hospital without any additional treatment and under medical supervision. Patients received the extract at successive doses of 30 (1 administration), 60 (2 administrations), 120 (4 administrations), and 240 (8 administrations) IR with $30 \mathrm{~min}$ between each dose. The dosing regimen is summarized in table 1 . The investigator recorded all adverse reactions occurring at each dose level (type of reaction, severity according to the classification of the European Academy of Allergology and Clinical Immunology [15], whether the reaction was local oral, gastrointestinal or systemic, time to onset after administration, reaction duration, measures taken, and relationship to the study drug). In order to capture late reactions, patients were maintained in observation until $60 \mathrm{~min}$ after the last dose of the ultra-rush regimen ( $90 \mathrm{~min}$ in the case of asthmatic patients). The protocol specified modifications to the induction dosing regimen according to adverse reactions. Thus, a patient would be discontinued from the study at any time if a serious adverse reaction occurred. If an adverse reaction occurred during the third dose, the first two doses of the induction regimen were to be repeated the following day and then the patient would increase the dose every subsequent day until reaching 8 applications per day provided the treatment was well tolerated. 
Table 2. Patient baseline characteristics $(n=218)$

\begin{tabular}{|c|c|}
\hline Mean age, years & 20.4 \\
\hline Aged $<15$ years, $n$ & $122(56.0 \%)$ \\
\hline \multicolumn{2}{|l|}{ Sex, $\mathrm{n}$} \\
\hline Male & $101(46.3 \%)$ \\
\hline Female & $117(53.7 \%)$ \\
\hline Family history of atopy & $107(49.1 \%)$ \\
\hline Diagnosis of asthma & $77(35.3 \%)$ \\
\hline Mean disease duration, years & 4.84 \\
\hline Total IgE, kU/l (mean, range) & $497.7(11.4-5,230)$ \\
\hline \multicolumn{2}{|l|}{ Specific IgE, kU/l (mean, range) } \\
\hline Dermatophagoides pteronyssinus & $52.4(1-100)^{\mathrm{a}}$ \\
\hline Dermatophagoides farinae & $44.5(0.7-100)^{\mathrm{b}}$ \\
\hline \multicolumn{2}{|l|}{ Skin prick tests, $\mathrm{mm}^{2}$ (mean, range) } \\
\hline Dermatophagoides pteronyssinus & $44.5(4-100)$ \\
\hline Dermatophagoides farinae & $46.9(4-225)$ \\
\hline
\end{tabular}

Patients with asthma underwent spirometry testing as an additional measure of safety. If patients suffered a decrease in peak expiratory flow of more than $20 \%$ with respect to baseline, they were not allowed to proceed to the next dose level. Blood pressure and pulse rate were measured before and after each dose.

After the induction phase, patients began to take the maintenance dose (recommended dose of 240 IR three times a week). In a subsequent visit approximately 2 weeks later, adverse reactions during the maintenance phase were recorded. In addition, a subjective assessment of tolerability (both patient and physician) was performed using a visual analogue scale ranging from 0 to 10 , with higher scores indicating better tolerability.

\section{Statistical Analysis}

Adverse events were presented as absolute and relative frequencies. For continuous variables (visual analogue scale and peak expiratory flow), means and standard deviations were calculated. No formal hypothesis testing was done.

\section{Results}

In total, 218 patients received at least 1 dose of the ultra-rush regimen and were included in the study. The mean age of the patients was 20.4 years (range 4-64 years). Of these, 117 were female participants (53.7\%) and $122(56.0 \%)$ were under 15 years old. A full summary of the baseline characteristics is given in table 2. On average, patients had been suffering from rhinitis symptoms for nearly 5 years and approximately one third had asthma. No patients discontinued the study due to adverse events, and no serious adverse events or life-threatening anaphylactic reactions were reported.

Safety of Ultra-Rush Sublingual Immunotherapy

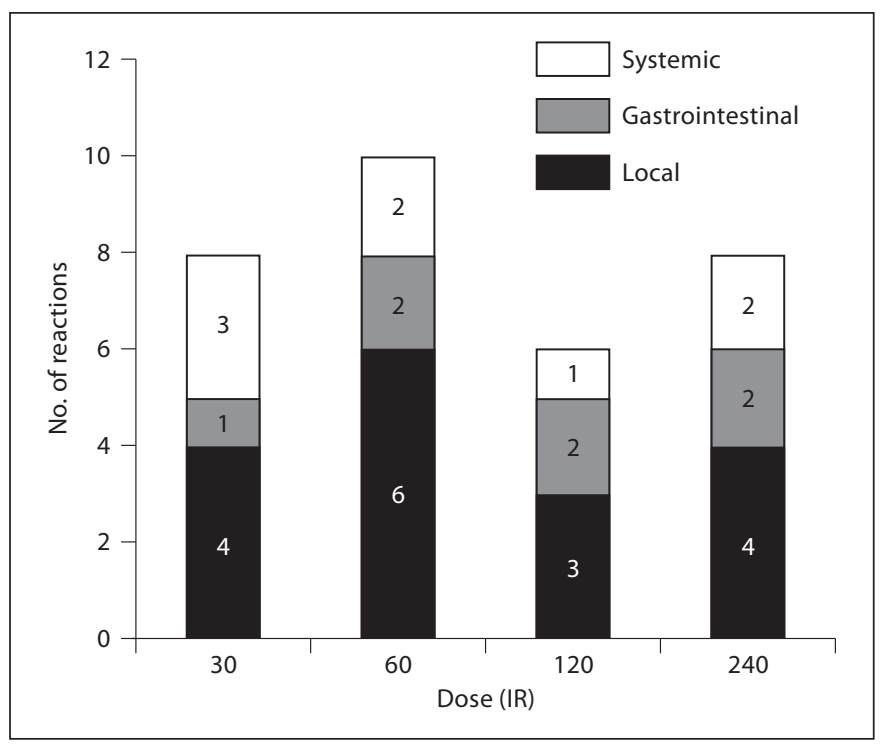

Fig. 1. Different types of adverse reactions according to dose administered. IR = Index of reactivity.

\section{Safety Results for the Ultra-Rush Phase at Hospital}

In total, 32 adverse reactions were reported in 27 patients, that is, 191 patients (87.6\%) did not experience any adverse reactions during the ultra-rush period. Of the patients with adverse reactions, 16 (59.3\%) were children. Five patients had to modify the ultra-rush regimen because of mild local adverse reactions. In two patients, doses had to be repeated; in one because of mouth itching after the application at $60 \mathrm{~min}$ (120 IR) and in another patient, also because of mouth itching after the application at $30 \mathrm{~min}$ (60 IR). In both cases, the regimen was successfully completed. In three other patients, administration was delayed (by $30 \mathrm{~min}$ or less) to allow resolution of a mild reaction from the previous dose. In one of these patients, three applications instead of four were administered at $60 \mathrm{~min}$. No other adverse reactions led to any modification in the dosing schedule.

Adverse reactions were classified as local oral, local gastrointestinal, and systemic.

Seventeen local oral reactions were reported in 13 patients (6.0\%). The greatest number of local reactions was observed after the 60 IR dose, although such reactions occurred at all doses during the ultra-rush regimen (fig. 1). The most frequent local reactions were labial or mouth itching.

As shown in table 3, seven local gastrointestinal reactions occurred in seven patients (five with gastrointesti- 
Table 3. Summary of adverse events reported during the study

\begin{tabular}{|c|c|c|c|c|}
\hline & \multicolumn{4}{|c|}{ Adverse events } \\
\hline & $\mathrm{n}=32$ & During ultra-rush SLIT administration & $\mathrm{n}=25$ & During maintenance \\
\hline \multicolumn{5}{|l|}{ Type } \\
\hline $\begin{array}{l}\text { Local } \\
\text { (oral) }\end{array}$ & 17 & $\begin{array}{l}\text { Mouth itching }(\mathrm{n}=13) \text {, labial itching }(\mathrm{n}=2) \text {, } \\
\text { mouth burning and itching }(\mathrm{n}=1) \text {, tongue itching } \\
(\mathrm{n}=1)\end{array}$ & 12 & $\begin{array}{l}\text { Mouth itching }(n=8) \text {, mouth edema }(n=2) \text {, } \\
\text { mouth angioedema }(n=1) \text {, mouth rash }(n=1)\end{array}$ \\
\hline $\begin{array}{l}\text { Local } \\
\text { (gastro- } \\
\text { intestinal) }\end{array}$ & 7 & $\begin{array}{l}\text { Gastrointestinal pain }(n=5) \text {, gastrointestinal pain, } \\
\text { flatulence and nausea }(n=1) \text {, nausea } \\
(n=1)\end{array}$ & 7 & $\begin{array}{l}\text { Epigastralgia }(n=2) \text {, gastrointestinal pain }(n= \\
2) \text {, nausea }(n=1) \text {, vomiting }(n=1) \text {, diarrhea } \\
(n=1)\end{array}$ \\
\hline Systemic & 8 & $\begin{array}{l}\text { Rhinitis }(n=3) \text {, general malaise }(n=1) \text {, general } \\
\text { malaise + vomiting }(n=1) \text {, dizziness }(n=1) \text {, } \\
\text { asthma }(n=1) \text {, dyspnea }(n=1)\end{array}$ & 6 & $\begin{array}{l}\text { Spots on face and neck }(n=1) \text {, hydrorrhea } \\
(n=1) \text {, blocked nose }(n=1) \text {, pharyngeal } \\
\text { symptoms }(n=1) \text {, nasal symptoms }(n=1) \\
\text { ear symptoms }(n=1)\end{array}$ \\
\hline \multicolumn{5}{|l|}{ Severity } \\
\hline Mild & 22 & $\begin{array}{l}\text { Mouth itching }(n=8) \text {, gastrointestinal pain }(n=3) \text {, } \\
\text { rhinitis }(n=2) \text {, general malaise }(n=1) \text {, general } \\
\text { malaise }+ \text { vomiting }(n=1) \text {, labial itching }(n=2) \text {, } \\
\text { mouth burning and itching }(n=1) \text {, tongue itching } \\
(n=1) \text {, dizziness }(n=1) \text {, gastrointestinal pain, } \\
\text { flatulence and nausea }(n=1) \text {, asthma }(n=1)\end{array}$ & - & - \\
\hline Moderate & 10 & $\begin{array}{l}\text { Mouth itching }(n=5) \text {, gastrointestinal pain }(n=2) \text {, } \\
\text { rhinitis }(n=1) \text {, dyspnea }(n=1) \text { nausea }(n=1)\end{array}$ & - & - \\
\hline \multicolumn{5}{|c|}{ Causal relationship } \\
\hline $\begin{array}{l}\text { Definite, } \\
\text { possible or } \\
\text { probable }\end{array}$ & 29 & $\begin{array}{l}\text { Mouth itching }(n=13) \text {, gastrointestinal pain }(n= \\
5) \text {, rhinitis }(n=3) \text {, labial itching }(n=2) \text {, general } \\
\text { malaise }(n=1) \text {, general malaise }+ \text { vomiting }(n=1) \text {, } \\
\text { mouth burning and itching }(n=1) \text {, tongue itching } \\
(n=1) \text {, gastrointestinal pain, flatulence and nausea } \\
(n=1) \text {, nausea }(n=1)\end{array}$ & - & - \\
\hline Improbable & 3 & Dizziness $(\mathrm{n}=1)$, asthma (1), dyspnea (1) & - & - \\
\hline
\end{tabular}

Where data were missing, the adverse events were imputed as mild in severity and the causal relationship definite. SLIT $=$ Sublingual immunotherapy.

nal pain; one with gastrointestinal pain, flatulence and nausea, and one with nausea).

Eight systemic reactions were reported in seven patients: three with rhinitis; one with general malaise; one with general malaise and vomiting; one with dizziness, and one episode of moderate dyspnea and asthma in a patient with mild asthma at baseline. The patient with asthma and dyspnea continued in the study without changing dose or delaying treatment so the patient was not considered at vital risk. General malaise and vomiting occurred during the observation period in hospital in an asthmatic patient (a 12-year-old male), but the patient continued with maintenance dosing. Likewise, all patients with rhinitis and the patient with general malaise continued in the study and suffered no further adverse reactions.

Two-thirds of all adverse events were considered to be mild by the investigators and none of these reactions were serious. In all cases, events resolved satisfactorily, without additional treatment.

Mean diastolic and systolic blood pressures and heart rates were similar to the values recorded at baseline

\section{Safety Results for the Follow-Up after Two Weeks of Maintenance Dosing}

After two weeks of maintenance dosing, 25 patients out of the 212 with data in the maintenance phase (12\%) reported experiencing at least one adverse reaction 
(mainly mouth itching), which were all mild or moderate (table 3).

The subjective tolerance according to both patients and investigators using the visual analogue scale was good (7.9 and 8.5, respectively, on a visual analogue scale).

\section{Patients with Asthma}

A little under half the adverse events were reported in the 77 asthmatic patients included in the study, although the profile of adverse events was similar to the overall population of the study. In addition, in these patients, peak expiratory flow did not decrease by more than $20 \%$ with respect to baseline at any of the doses of the ultrarush regimen.

\section{Discussion}

The primary attraction of SLIT is its safety and ease of administration in comparison with subcutaneous immunotherapy [2]. The first sublingual therapies included updosing lasting up to a couple of weeks in an approach that mimicked the regimens used in subcutaneous immunotherapy. However, encouraged by the good tolerance of sublingual therapies, clinicians began to seek other regimens more agreeable to patients.

One possibility is to completely eliminate the induction phase; thus, Rodriguez et al. [16] reported a doubleblind, placebo-controlled study of 135 patients diagnosed with rhinitis with/without asthma who were treated with grass and house-dust mite SLIT. One group received 10 days' updosing whereas the other received placebo updosing and started directly on the maintenance dose. Although the number of adverse events in the group without updosing was slightly higher (1.45 vs. $1.10 \%)$, this did not appear to lead to an increased number of withdrawals.

The use of ultra-rush regimens - an induction phase compressed into less than a couple of hours - represents a compromise between conventional updosing and its complete elimination. The ultra-rush SLIT regimens are administered under strict monitoring of an allergist perfectly aware and used to managing allergy reactions, in a medical center with the necessary resources to deal with any life-threatening events such as anaphylactic reactions. The maintenance doses are then administered in the patient's home without any medical supervision (it is of utmost importance that this part of the regimen is well tolerated). None of the studies performed to date have reported any life-threatening adverse events (such as ana- phylactic shock) at the doses recommended by the manufacturers [17], and a pilot study of the feasibility of ultrarush SLIT in 679 patients using different commercial allergen extracts did not identify any safety issues [18]. An observational study in 193 children and adolescents with allergic rhinitis due to grass or tree pollen was conducted to evaluate the safety and tolerability of an similar ultra-rush SLIT regimen to that performed in our study, and predominantly mild and local adverse events were reported [19]. Likewise, a study of an ultra-rush incremental dose regimen with Juniperus ashei allergen extract in patients allergic to Cupressus sempervirens and Cupressus arizonica failed to identify any specific safety concerns [9]. A similar study was carried out by Stelmach et al. [11] indicating that high-dose ultra-rush co-seasonal SLIT given for 2 years was safe and reduced a multiple symptom-medication score. One case of anaphylactic shock was identified in a 16-year-old Polish girl with controlled asthma attributed to use of SLIT with a standardized extract of house dust mites [20]. The event occurred in the third year of maintenance dosing, but 3 weeks after ending regular maintenance dosing, and after administering, for unknown reasons, a dose of 60 drops (6 times the maintenance dose). A further case of a serious anaphylactic reaction has been reported from post-marketing surveillance in a patient who received sublingual therapy with multiple allergens from extracts available commercially in the United States [21].

In the present study, five adverse reactions requiring modification of the induction dosing regimen were reported during the ultra-rush phase. In another observational study in a clinical practice setting of ultra-rush titration in 245 patients with allergic rhinitis due to tree pollens (birch, alder, hazel), 14 patients (5.7\%) switched to standard updosing due to adverse events [22]. However, other studies have reported lower drop-out rates during similar ultra-rush titrations, thus Merk and Sieber [23] reported that three of 345 ultra-rush titrations in patients with allergic rhinitis to grasses $(0.9 \%)$ did not reach the maintenance dose, and Gammeri et al. [13] reported no changes in dosing in an ultra-rush phase lasting $20 \mathrm{~min}$ in patients with rhinitis or asthma due to house dust mites, Parietaria, or Timothy grass. Most adverse reactions during the ultra-rush phase of the present study were local [17 of $32(53 \%)]$ and the 8 systemic reactions were of mild or moderate severity. This also reflects patterns seen in previous studies. Thus, in a study of $245 \mathrm{pa}-$ tients with allergic rhinitis against tree pollens treated with the same ultra-rush induction regimen as ours [22], of a total of 56 adverse reactions, 30 were local, 14 sys- 
temic, and 9 gastrointestinal symptoms. We note that $59.3 \%$ of the patients with adverse reactions were aged under 15 years. This is higher than the percentage of patients under 15 in the overall sample (53.7\%), but the difference does not seem large enough to indicate that children tolerate the regimen worse than adults.

At the follow-up visit after 2 weeks of maintenance therapy, SLIT continued to be well tolerated, as indicated by the low number of adverse events. This is in line with the study by Ott et al. [10], who also noted that most of the adverse reactions reported during maintenance were not considered to be related to the study drug.

Immunotherapy in patients with asthma has been controversial, particularly in view of the possibility of anaphylaxis $[1,24]$, and so special attention should be paid to this subgroup. In the present study, the profile of adverse events for the 77 asthmatic patients included did not differ substantially from the overall profile of adverse events. In addition, peak expiratory flow did not decrease by more than $20 \%$ with respect to baseline at any of the doses of the ultra-rush regimen. According to the results of the present study, there is no evidence that patients with asthma tolerate SLIT worse than patients without asthma. This is in agreement with other studies of other allergens that have included patients with asthma $[10,11]$.

This study has the limitations of a non-randomized controlled trial, nevertheless, the main aim was to demonstrate the tolerability of the ultra-rush regimen in SLIT with Dermatophagoides allergens in daily clinical practice. Although a control group would have been desirable, an observational study can nevertheless allow inclusion of patients treated as they are in everyday clinical practice, and provide valuable 'real-world' information.

In conclusion, the results of the present study with a relatively large sample $(n=218)$ reinforce those reported in previous studies (both randomized and observational) with a range of allergens administered in an ultrarush building-up dose regimen. High doses of Dermatophagoides extract (total cumulative dose of 450 IR administered in $90 \mathrm{~min}$ ) in patients with rhinitis and asthma due to mites were well tolerated with a low rate of adverse reactions in the building-up phase and few adverse reactions reported after two weeks follow-up. However, despite the low rate of adverse events in ultrarush building-up dose regimen, some systemic reactions have been registered. Given that treatment of mite allergy is not subject to the same time limits as other seasonal allergens, and the fact that nowadays the maximal dose for SLIT is reached in a few days instead of weeks as used to be the case, the allergist must asses the benefit of the application of ultra-rush building-up regimens for allergic diseases caused by house dust mites, taking into account this is a perennial treatment. Thus, more ultrarush regimen may improve adherence because of the greater convenience of a single session and greater contact with healthcare staff, who are in a position to offer counseling and advice.

\section{Acknowledgment}

The authors thank Content Ed Net Madrid for editorial assistance.

\section{References}

1 Amin HS, Liss GM, Bernstein DI: Evaluation of near-fatal reactions to allergen immunotherapy injections. J Allergy Clin Immunol 2006;117:169-175.

-2 Canonica GW, Passalacqua G: Noninjection routes for immunotherapy. J Allergy Clin Immunol 2003;111:437-448.

- 3 Andre C, Vatrinet C, Galvain S, Carat F, Sicard H: Safety of sublingual-swallow immunotherapy in children and adults. Int Arch Allergy Immunol 2000;121:229-234.

4 Wilson DR, Lima MT, Durham SR: Sublingual immunotherapy for allergic rhinitis: systematic review and meta-analysis. Allergy $2005 ; 60: 4-12$.
5 Calamita Z, Saconato H, Pela AB, Atallah AN: Efficacy of sublingual immunotherapy in asthma: systematic review of randomizedclinical trials using the cochrane collaboration method. Allergy 2006;61:1162-1172.

-6 Bousquet J, Van Cauwenberge P, Khaltaev N: Allergic rhinitis and its impact on asthma. J Allergy Clin Immunol 2001;108:S147-S334.

7 Khinchi MS, Poulsen LK, Carat F, Andre C, Hansen AB, Malling HJ: Clinical efficacy of sublingual and subcutaneous birch pollen allergen-specific immunotherapy: a randomized, placebo-controlled, double-blind, double-dummy study. Allergy 2004;59:4553 .
8 Bousquet J: Sublingual immunotherapy: validated!! Allergy 2006;61(suppl 81):S5-S6.

$\$ 9$ Vervloet D, Birnbaum J, Laurent P, Hugues B, Fardeau MF, Massabie-Bouchat YP, Aferiat-Derome A, Andre C: Safety and efficacy of Juniperus ashei sublingual-swallow ultrarush pollen immunotherapy in cypress rhinoconjunctivitis: a double-blind, placebocontrolled study. Int Arch Allergy Immunol 2007;142:239-246.

10 Ott H, Sieber J, Brehler R, Folster-Holst R, Kapp A, Klimek L, Pfaar O, Merk H: Efficacy of grass pollen sublingual immunotherapy for three consecutive seasons and after cessation of treatment: the ECRIT study. Allergy 2009;64:179-186. 
-11 Stelmach I, Kaczmarek-Wozniak J, Majak P, Olszowiec-Chlebna M, Jerzynska J: Efficacy and safety of high-doses sublingual immunotherapy in ultra-rush scheme in children allergic to grass pollen. Clin Exp Allergy 2009;39:401-408.

$\checkmark 12$ Tripodi S, Di Rienzo Businco A, Benincori N, Scala G, Pingitore G: Safety and tolerability of ultra-rush induction, less than one hour, of sublingual immunotherapy in children. Int Arch Allergy Immunol 2006;139: 149-152.

-13 Gammeri E, Arena A, D’Anneo R, La Grutta S: Safety and tolerability of ultra-rush $(20$ min) sublingual immunotherapy in patients with allergic rhinitis and/or asthma. Allergol Immunopathol (Madr) 2005;33:221-223.

-14 Cox LS, Larenas Linnemann D, Nolte H, Weldon D, Finegold I, Nelson HS: Sublingual immunotherapy: a comprehensive review. J Allergy Clin Immunol 2006;117:1021-1035.

-15 Malling HJ, Weeke B: Position paper: immunotherapy. Allergy 1993;48(suppl 14):9-35.
6 Rodriguez F, Boquete M, Ibanez MD, de la Torre-Martinez F, Tabar AI: Once daily sublingual immunotherapy without updosing: a new treatment schedule. Int Arch Allergy Immunol 2006;140:321-326.

17 Gidaro GB, Marcucci F, Sensi L, Incorvaia C Frati F, Ciprandi G: The safety of sublingualswallow immunotherapy: an analysis of published studies. Clin Exp Allergy 2005;35: 565-571.

18 Rossi RE, Monasterolo G: A pilot study of feasibility of ultra-rush (20-25 min) sublingual-swallow immunotherapy in 679 patients (699 sessions) with allergic rhinitis and/or asthma. Int J Immunopathol Pharmacol 2005;18:277-285.

19 Seidenberg J, Pajno GB, Bauer CP, La Grutta S, Sieber J: Safety and tolerability of seasonal ultra-rush high-dose sublingual-swallow immunotherapy in allergic rhinitis to grass and tree pollens: an observational study in 193 children and adolescents. J Investig Allergol Clin Immunol 2009;19:125-131.
20 Blazowski L: Anaphylactic shock because of sublingual immunotherapy overdose during third year of maintenance dose. Allergy 2008;63:374.

-21 Dunsky EH, Goldstein MF, Dvorin DJ, Belecanech GA: Anaphylaxis to sublingual immunotherapy. Allergy 2006;61:1235.

22 Sieber J, Merk HF: Tolerability and effectiveness of seasonal SLIT with ultra-rush titration: an open prospective observational study. XXIII Congress of the EAACI, 2004 (abstract book):140-141.

23 Merk HF, Sieber J: Safety of high-dose sublingual immunotherapy with ultra-rush titration: New follow-up data from a DBPC study in grass-pollen allergic patients. XXIII Congress of the EAACI, 2004 (abstract book): 4 .

24 Abramson MJ, Puy RM, Weiner JM: Allergen immunotherapy for asthma. Cochrane Database Syst Rev 2000:CD001186. 